\title{
AKTUALISASI \\ PENDIDIKAN AGAMA KRISTEN DALAM GEREJA SEBAGAI DASAR PELAKSANAAN MISI
}

Winda Resti Ananda

\section{INSTITUT AGAMA KRISTEN NEGERI TORAJA}

windarestiananda02@gmail.com

\begin{abstract}
ABSTRAK: Christian Religious Education is a strong, firm, and fundamental Christian commitment in church ministry. If the church ignores teaching, then the church becomes static, lives in ignorance of faith, and means nothing. The task of the church is to equip and teach the members of the congregation to remain faithful to God and carry out his commands. This task remains relevant and must be continuously updated according to the demands of needs, developments, challenges, and contexts. With education, the church helps believers so that they can live as disciples of Christ, be able to apply their faith in daily life, and make Christian Religious Education the basis for carrying out missions. A person's spiritual growth does not occur because of his status as a Christian, or because of his faithfulness to follow church services. Therefore, the entire existence of the church in its ministry must be centered on planned and continuous teaching.
\end{abstract}

Keyword: Pendidikan, Gereja, Misi, Allah, Pelaksanaan

\section{PENDAHULUAN}

Dalam konteks Indonesia, Pendidikan Kristen dalam sebuah Gereja menjadi sangat penting khususnya dalam melaksanakan misi Kristen. Asal mula misi bermula karya Allah Bapa yang memisikan Anak-Nya (Yesus) datang kedunia (Yoh. 3:16) dengan suatu tindakan untuk menyelamatkan manusia ${ }^{1}$. Gereja merupakan sebuah organisasi sekaligus sebuah sistem yang menjalankan fungsinya secara dinamis, karena gereja merupakan suatu kehidupan bersama yang mempengaruhi lingkungannya, sekaligus dipengaruhi oleh lingkungannya. Ada banyak gereja yang megah, besar, juga memiliki banyak jemaat, tetapi tidak memaksimalkan pendidikan dan pengajaran dengan baik. Akibatnya gereja itu tidak tertata, dan tidak bisa memaksimalkan fungsi gereja itu sebagaimana mestinya. Perlunya Pendidikan Kristen di dalam gereja supaya tidak terjadi kekacauan, tetapi tertata dengan baik. Setiap gereja yang kecil maupun besar yang harus dilakukan ialah menjadikan pendidikan itu sebagai dasar dalam melaksanakan misi Allah di tengah-tengah persekutuan kita, sehingga

\footnotetext{
${ }^{1}$ Bambang Eko Putranto, "Misi Kristen : Menjangkau Jiwa Menyelamatkan Dunia” (2007): 13.
} 
gereja mempunyai sistem yang mantap dan tersusun secara otomatis fungsi gereja sebagai gereja tubuh Kristus akan berjalan dengan baik gereja tersebut yang sesuai kehendak Tuhan. Itulah sebabnya gereja sebagai dasar pelaksaaan misi Kristen. Pendidikan tidak bisa dipisahkan dari kehidupan dan pelayanan gereja. Sebagai agen pendidik, gereja harus memberi tempat yang luas bagi pendidikan. Mengaktualisasikan diri dan terus bersandar pada pertolongan Roh kudus, gereja harus terus memikirkan, merancangkan, mengelolah dan melaksanakan pendidikan didalam jemaat.

\section{TUJUAN DAN MANFAAT}

Tujuan dari penulisan ini adalah untuk menunjukkan begitu pentingnya PAK dalam sebuah gereja. Pendidikan, pengajaran dalam jemaat amat penting dilaksanakan, agar jemaat mengetahui dengan jelas keselamatan didalam Kristus adalah Juruselamat kepada setiap orang yang percaya dan beriman kepada-Nya, bahwa dosa-dosanya diampuni dan dihapuskan dikayu salib (1 Petrus 2:24), dan lewat keselamatan itu setiap orang percaya dipanggil untuk hidup dalam ketaatan kepada Kristus.

\section{PEMBAHASAN}

\section{A. Pentingnya pendidikan dalam Gereja}

Pendidikan sebagai sebuah proses, kini ditantang untuk dapat menginternalisasi makna dan berbagai perubahan yang mendasar menyangkut orientasi cara pandang, oleh sebab itu dibutuhkan adanya transformasi pendidikan ${ }^{2}$. Pentingnya tugas mendidik dalam gereja adalah dalam rangka pembentukan dan peningkatan kualitas iman, moral dan etis warga jemaat. Dengan demikian warga jemaat didorong, dibimbing, dan dilatih untuk takut akan Allah. Pendidikan dan pengajaran akan membawa warga jemaat kepad perjumpaan pribadi dengan Allah didalam Yesus Kristus. Oleh karena itu, gereja harus terus menerus memikirkan arah pendidikan didalam jemaat. Pendidikan harus mampu membawa warga jemaat memiliki spiritualitas yang tinggi, berkomitmen dan memiliki pengakuan iman yang teguh bahwa Yesus Kristus adalah Mesias Anak Allah yang Maha tinggi.

B. Aktualisasi Pendidikan sebagai dasar pelaksanaan misi

Jemaat yang mendapat pengajaran firman Allah akan bertumbuh dalam iman, menggunakan pendidikan dan pengajaran sebagai dasar dalam bermisi. Buah dari pengajaran

\footnotetext{
${ }^{2}$ Rannu Sanderan, "Disiplin Asketisme Dan Harmoni: Kontribusi Dispiplin Diri Bagi Pemngembangan Pendidikan Kristen," Jurnal PAK STAKN Toraja (n.d.).
} 
itu akan dipetik dan akan nampak dalam kehidupan pribadi, keluarga, maupun dalam hubungannya dengan sesama. Kehidupan warga jemaat akan berdiri kokoh diatas firman Allah, imannya akan menjadi stabil karena sudah diajar prinsip-prinsip dasar iman kristen. Mereka menjadi anggota jemaat yang dapat diandalkan karena telah diteguhkan dalam kasih, pengetahuan, dan hikmat firman Allah yang hidup. Pendidikan akan memimpin warga jemaat menuju kedewasaan didalam Kristus, serta memampuhkan mereka untuk melakukan apa yang Kristus perintahkan (Mat 28:19). Dengan adanya PAK sebagai dasar pelaksanaan misi dam gereja, warga jemaat dapat menjalani hidupnya dengan sukacita, berkemenangan, menikmati berkat-berkat kehidupan yang dijanjikan Allah, hidup dalam doa, berkemenangan, serta mampu menjadi saksi-saksi Kristus. Layaknya pendidikan formal di sekolah pendidikan iman tidak hanya terjadi dalam ruangan lingkup gereja. Namun pada kenyataannya kebanyakan Iman timbul dari budaya. Identitas budaya banyak memberikan kontribusi dalam pendidikan karakter sehingga manusia menjadi manusia yang dewasa dan berbudaya $^{3}$. Jenis dan bentuk pendidikan dapat dilaksanakan yaitu pendidikan anak-anak, pendidikan remaja, pendidikan pemuda, pendidikan orang dewasa, pendidikan pengerja gereja dan pendidikan tumbuh bersama. Pembagian ini sesuai dengan komisi-komisi pembinaan yang terdapat dalam jemaat. Namun yang akan dibahas penulis hanya pendidikan anak dan kaum wanita

\section{Pendidikan anak-anak}

Kepentingan anak menjadi semakin terabaikan karena anak hanya belajar untuk menyenangkan orangtua dan guru dengan mendapatkan nilai baik, juga untuk memenuhi kebutuhan industri ${ }^{4}$. Kesempatan bagi anak-anak untuk berbuat lebih jauh mengembangkan diri bisa terhambat akibat problem situasi keluarga yang kurang memiliki exemplaritas 5 . Dengan memberi pengajaran iman, diharapkan anak-anak tahu dampak dari sikap taat dan resiko dari perbuatan memberontak. Pendidikan iman kepada anak dimaknai sebagai proses pembekalan pengetahuan, nilai, dan penciptaan karakter tidak meberi ruang pada insting namun realitanya itu dapat mendorong manusia untuk mengakui ketidakberdayaan diri sendiri sebagai manusia dan atas hal tersebut dijadikan sebagai dasar ketidakpastian

\footnotetext{
${ }^{3}$ Rannu Sanderan, "Heuristika Dalam Pendidikan Karakter Manusia Toraja Tradisonal," Bia: Jurnal Teologi dan Pendidikan Kristen Kontekstual 3, no. 2 (n.d.): 310.

${ }^{4}$ Y. Dedy Pradipto, "Belajar Sejati Vs Kurikulum Nasional, Kontestasi Kekuasaan Dalam Pendidikan Dasar" (2007): 62.

${ }^{5}$ Sanderan Rannu, “"Exemplary Menemukenali Kunci Pendidikan Iman Anak Dalam Keluarga Dan Pembelajaran Agama Di Sekolah" (2021).
} 
spiritualitas dan realigi ${ }^{6}$. Gereja harus senantiasa menyadari bahwa pelayanan bagi anak-anak adalah dalam rangka membimbingnya menjadi murid kristus dalam tahap penrkembangannya. Oleh karena itu pendidikan terhadap anak haruslah bersikap penginjilan, dengan demikian anak-anak dimungkinkan untuk mengubah setelah menerima Tuhan Yesus sebagai juruslamatnya.

\section{$>$ Pendidikan kaum wanita}

Kaum wanita memiliki peran ganda dalam hidupnya yang yaitu didalam keluarga dan gereja. Didalam keluarga menjadi seorang ibu bagi seluruhh isi keluarganya, memberi pengayoman kasih sayang dan perhatian, serta mengurus yang berkaitan dengan rumah sebagai tempat tinggal seluruh keluarga. Perjuangan untuk mengupayakan kesejajaran antara laki-laki dengan perempuan dalam jabatan gerejawi harus disadari dengan melakukannya berdasarkan prinsip kemitraan ${ }^{7}$. Sudah saatnya gereja merubah pola kepemimpinan yang lama, di mana kaum perempuan dianggap sebagai orang-orang yang lemah dan tidak dapat memegang jabatan dalam kepemimpinan (Evang Darmaputera, 1997). Digereja wanita dapat terlibat aktif dalam berbagai bentuk pelayanan. Berkaitan dengan hal tersebut, maka pengajaran kaum wanita didalam gereja haruslah diarahkan kepada peningkatan mutu dan kualitas iman agar kaum wanita dapat menjadi teladan ditengah-tengah keluarga maupun jemaat.

\section{KESIMPULAN}

Pendidikan Agama Kristen sebagai pelaksanaan misi Kristen, dan menjadi tugas utama yang disediakan Allah untuk mengenal Dia, didalam gerejalah orang-orang percaya berkumpul dan beribadah serta mempelajari firman Allah. Gereja ditempatkan oleh Allah ditengah-tengah dunia untuk memberitakan kabar kesukaan, sehingga dalam kehadirannya gereja menjalankan dua misi sekaligus yaitu "didasche" (pengajaran) dan "karigma" (pemberitaan). Pengajaran (didasche) bersumber dari pemberitaan (karigma). Setelah orangorang bertemu dengan Kristus, mereka memiliki hidup baru, bersekutu dengan-Nya dan hidupnya dibangun didalam persekutuan dengan Dia. Untuk membawa orang-orang percaya kepada pengenalan dan kasih akan Kristus, gereja harus melaksanakan pengajaran terusmenerus.

\footnotetext{
${ }^{6}$ Rannu Sanderan, "Intuisi: Pemahaman Gagasan Hans-George Gadamer Tentang Intuisi Sebagai Supralogika," Jurnal Ilmiah Relligiosity Entity Humanity (JIREH)) 2, no. 2 (n.d.): 114-125.

${ }^{7}$ Rannu Sanderan, “Jabatan Gerejawi Dan Peran Perempuan Dalam Pelayanan Di Gereja," Jurnal Masakke: Paskasarjana STAKN Toraja, jurusan Kepemimpinan Kristen 1 (2014): 2-3.
} 


\section{DAFTAR PUSTAKA}

Pradipto, Y. Dedy. “Belajar Sejati Vs Kurikulum Nasional, Kontestasi Kekuasaan Dalam Pendidikan Dasar" (2007): 62.

Putranto, Bambang Eko. "Misi Kristen : Menjangkau Jiwa Menyelamatkan Dunia” (2007): 13.

Rannu, Sanderan. “"Exemplary Menemukenali Kunci Pendidikan Iman Anak Dalam Keluarga Dan Pembelajaran Agama Di Sekolah” (2021).

Sanderan, Rannu. "Disiplin Asketisme Dan Harmoni: Kontribusi Dispiplin Diri Bagi Pemngembangan Pendidikan Kristen.” Jurnal PAK STAKN Toraja (n.d.).

__. "Heuristika Dalam Pendidikan Karakter Manusia Toraja Tradisonal." Bia: Jurnal Teologi dan Pendidikan Kristen Kontekstual 3, no. 2 (n.d.): 310.

—. "Intuisi: Pemahaman Gagasan Hans-George Gadamer Tentang Intuisi Sebagai Supralogika.” Jurnal Ilmiah Relligiosity Entity Humanity (JIREH)) 2, no. 2 (n.d.): 114125.

__. "Jabatan Gerejawi Dan Peran Perempuan Dalam Pelayanan Di Gereja." Jurnal Masakke: Paskasarjana STAKN Toraja, jurusan Kepemimpinan Kristen 1 (2014): 2-3. 